\title{
Teaching Speech Acts in EFL Classrooms: An Implicit Pedagogy
}

\author{
FENG Yi-xuan \\ Shanghai Institute of Technology, Shanghai, China
}

\begin{abstract}
Language teaching is a combination of teaching syntax, content of language in use, and the social background of that language. As the study of the act in speech, speech acts naturally exist in social and interpersonal discourses. Thus it is of vital importance to let language learners to acquire its concept and principles. This paper is a brief introduction to the theories and approaches on speech acts as well as its application for ELT pedagogy. The paper is made up of three parts. In the first part, former investigations and theories on speech acts would be introduced and discussed. The second part is a discussion on communicative competence in English language teaching. In the third part, two sample tasks of implicit pedagogy for speech acts would be introduced. A conclusion of teaching speech acts implicitly is given out in the fourth part.
\end{abstract}

Keywords: speech act, communicative competence, language teaching

\section{An Introduction to Speech Acts}

Originated from Austin (1962), "Speech Act Theory said that the action performed when an utterance is produced can be analysed on three different levels" (Cutting, 2008, p. 13). These three levels, from Austin's (1962, p. 108) description, are locutionary act, illocutionary force, and perlocutionary effect. Locutionary act is "roughly equivalent to 'meaning' in the traditional sense" (Austin, 1962, p. 108). This definition does not seem very clear. From my personal interpretation, the locutionary act is the literary meaning or facial meaning of an utterance.

Austin (1962, p. 14) defines illocutionary force as the force of the speaker of certain utterance such as informing, ordering, warning, and undertaking. Accordingly, the relationship between locutionary act and illocutionary force can be regarded: The former is the meaning of the utterance; the latter is about the force of the utterance. However, Searle (1968) argued that there is no real distinction between locutionary acts and illocutionary acts. He (1968) explains "Where a certain force is part of the meaning, where the meaning uniquely determines a particular force, there are not two different acts but two different labels for the same act" (p. 407). Searle's critics on the relationship between locutionary and illocutionary seem not very convincing. This would be because the facial meaning and the action of the speaker through a certain utterance; from my personal understanding, there would sometimes be different labels for the same act, however, sometimes they would be two different things. The features of intercultural communication would be obvious in this dimension, especially in indirect speech acts, which would be discussed in the latter part of the paper.

FENG Yi-xuan, associate lecturer, MSc TESOL, School of Foreign Languages, Shanghai Institute of Technology. 
Following Austin's (1962, p. 108) definition on perlocutionary effect, Cutting (2008, p. 14) uses a modern way to explain perlocutionary act as the effect on the hearer, or the hearer's reaction of a certain utterance. Davis (1979) summarized Austin's theory on illocutionary act as "illocutionary acts are connected to effects in three ways: securing uptake, taking effect, and inviting a response which distinguishes them from perlocutionary acts" (p. 38). Although he argued later in the paper that "these three features do not apply to all illocutionary acts and so cannot be used to mark off illocutionary from perlocutionary acts" (Davis, 1979, p. 38), as far as I am concerned, it is not complex to distinguish perlocutionary acts from illocutionary ones in certain utterances. Perlocutionary acts is the effect on the hearer's reaction while illocutionary is the speaker's motivation and they are in a causal relationship. Just as Brown and Yule's (1983) description, an illocutionary act is "the speaker could be seen to have performed some act" and a perlocutionary act "can be described in terms of the effect which the illocutionary act, on the particular occasion of use, has on the hearer" (p. 232).

Among the three levels of speech act theory, illocutionary is the center of researches and various literature on illocutionary acts can be found. The most outstanding theory would be Searle's classification of illocutionary acts. Searle (1976) points out that "The basic unit of human linguistic communication is the illocutionary act" (p. 1). Based on illocutionary point, direction of fit, and expressed psychological state, illocutionary acts can be divided into five kinds: representatives/assertives, directives, commissives, expressive, and declarations. Searle (1976, pp. 10-13) has given out clear definitions of the five kinds of illocutionary acts. Representative is "the point or purpose of the members of the representative class is to commit the speaker to something's being the case, to the truth of the expressed proposition". Directives refer to "the illocutionary point of these consists in the fact that they are attempts by the speaker to get the hearer to do something" link with perlocutionary acts. The illocutionary point of expressive is "to express the psychological state specified in the sincerity condition about a state of affairs specified in the propositional content". Commissives acts are those illocutionary acts whose point is to commit the speaker to some future course of action.

Another classification in speech act theory is direct speech acts and indirect speech acts. According to Cutting (2008), "a speaker using a direct speech act wants to communicate the literal meaning that the words conventionally express; there is a direct relationship between the form and function" (p. 17). On the contrary, an indirect speech act is to communicate "a different meaning from the apparent surface meaning; the form and function are not directly related" (Cutting, 2008, p. 17). Two approaches of indirect speech would be shown here. The first approach was raised by Gordon and Lakoff (1975), which treated indirect speech acts as the way on request. However, Brown (1980) points out that this approach "associated with request are incomplete, since they lack any mention of obligation relationships" (p. 151). Another approach is raised by Searle (1975), which is valuable and "has succeeded in accounting for a broad range of speech acts" (Brown, 1980, p. 151). Searle (1975, pp. 6-61) gives out the issue to form a successful indirect speech: Speakers and hearers must have shared background information.

To be specific, Clark (1979, p. 431) lists six major properties of indirect speech acts as multiplicity of meanings, logical priority of meanings, rationality, conventionality, politeness, and purposefulness. As far as I am concerned, intercultural communication would be focused on this aspect. For this reason, politeness principle can be connected with speech acts from this perspective. To sum up, using indirect speech, as far as I am concerned, is connected with social relationships. This would be shown in the next part.

There are also some other approaches about the study of speech acts. Like felicity conditions, which are raised by Austin (1962), illustrate that all persons should recognize the context and the roles of participants, 
carry out action completely, have the right intentions, and not be pretending and understand the language. Brown and Yule (1983, p. 1) raise the approach of macro functions of communication competence. This approach divides communication competence into two macro functions: transactional function, which "language serves in the expression of "content", and interactional function "involved in expressing social relations and personal attitudes". My personal view towards macro functions lies in its connection with Austin's speech act theory. In an utterance in which three levels of acts are all involved, the locutionary act would be purely transactional and illocutionary or perlocutionary acts would cover both functions.

Although speech act theory is well established, there are two main limitations. The first is that "when we try to categorize utterances in terms of speech acts, we often find that there is an overlap, that one utterance can fall into more than one macro-class" (Cutting, 2008, p. 20). The second limitation is that some utterances cannot be included into any category.

For the intercultural dimension, Cutting (2008) points out that "differences in speech ace conventions can cause communication difficulties" (p. 19). From my personal perspective, these difficulties would be originated from Austin's felicity conditions, especially the gaps in language competence. As discussed in the former part, indirect speech acts would be most highlighted under intercultural contexts. Searle (1975) suggests one problem of indirect speech acts is "the problem of how it is possible for the speaker to say one thing and mean that but also to mean something else" (p. 60). Although he does not mention the context of indirect speech acts, the situation must be a monolingual one, hence, the speaker and the hearer share the same language and cultural background. From this point, I would like to infer that this problem would be more serious for intercultural communications because there must be some language and cultural gaps between the speaker and the hearer.

\section{Teaching Communicative Competence in the Language Classroom}

Leung (2005) points out the two elements of communicative competence: linguistic competence and pragmatic competence. Linguistic competence, such as syntax and phonology, is generally believed as contributions to speakers' language accuracy and fluency. How accurate and fluent one learner speaks that language is usually regarded as standards of one's language competence by the society. On the contrary, pragmatic competence, which means the use of language under certain context, is mainly connected with language appropriateness, which "depends on sufficient linguistic and pragmatic knowledge, as well as on overall strategic capacities to implement the knowledge in communicative interaction" (Taguchi, 2006, p. 514). Bachman (1990, p. 85) creates the term "sociolinguistic competence" as a part of communicative competence, which "consists of socio-cultural rules and rules of discourse".

From a wider concept of communicative competence to a more specific pragmatical point, Boxer and Pickering (1993) suggest “appropriate speech behaviour will rely heavily on those societies' own rules" (p. 45). This approach highlights the role of sociolinguistic competence in the appropriateness. Accordingly, in EFL classes, providing information about the context of the target language, such as social rules, should be treated as a central task throughout the whole teaching process. In the first part of the paper, intercultural dimension of speech act theory is discussed and the misunderstandings of intercultural speech acts lie in different social rules between speakers and hearers. This would again show the importance of teaching social rules of the target language. The social rules decide the speech acts in different languages. Taking interactional function of speech acts as an example, Chinese people always begin a conversation with "Have you had your meal?"; while British people always start talks with commenting on the weather. In order to make students get used to the speech act 
in target language, a social rule should be first taught by teachers.

In order to teach students the social rules of the target language, using authentic sources in the class is suggested by Larsen-Freeman (2000). Zhao and Throssell (2011, p. 92) explain that using authentic material not only refers to audio or video materials, but a macro concept, which means "learners should practice the target language in real life to achieve communicative purposes". In addition, adding situational role-play games is highly recommended by Peterson and Coltrane (2003). As far as I am concerned, adopting situational role play game is suitable for young learners because this kind of activities would raise children's interest so that they would be fully motivated. On the contrary, authentic source would not match young learners and beginners. For young learners and beginners, authentic material would be too difficult for them to understand. However, this would be a perfect match with advanced learners because advanced learners' linguistic competence is high enough to understand authentic materials. Authentic material can serve the advanced learners' shortage of pragmatic competence. Accordingly, speech acts should be taught explicitly to the beginners, while advanced learners should be suggested to learn it implicitly.

\section{Sample Activities for Acquiring Speech Act Theory in EFL Classrooms}

In the next part, I would design two simple semi-structured tasks for beginners and advanced learners to learn how to use and understand indirect speech. Different kinds of tasks should be adopted in terms of different levels of the language learners. In this section, I would just briefly design three sample class activities for language beginners and advanced learners.

For learners at the beginner level, role-play games are always adopted by teachers because they are of interests and easy to control. Role play games can be further developed into a competition between groups. For example, students can be divided into groups and each group covers two students. The teacher should prepare several cards with roles and situations written on it. The cards can be randomly delivered to each group. Here is an example for the card:

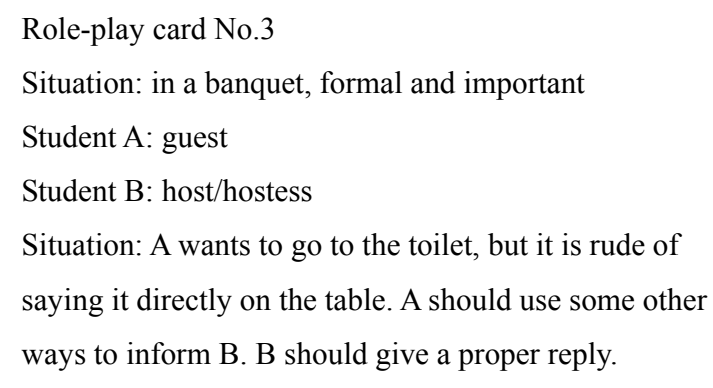

Figure 1. Sample card for the role play.

Since this activity is set for learners at a beginner level, explicit guidance of the social rules such as table manners should be given before the preparation. During the preparation procedure, the teacher should go to different groups to offer certain help. For example, if a group gets the card like Figure 1, group members are discovered being puzzled about the given situation, then the teacher can give the students some hints such as euphemism ("Nature calls" for example).

Instead of role-play games, I suggest that the task for advanced learners should be more focused on the function of speech acts. As what has been mentioned in the second part, authentic materials can be introduced 
to the SLA classrooms for advanced learners. For example, in the class, the teacher could bring in authentic video clips which can clearly show the rules and principles of speech act theory (TV series and movies as examples). The difficulty of the visual materials should be proper for most students in the classroom. If not, related subtitles (with translations if necessary) should also be included. Instead of directly showing the video clips to the class, guidance is of importance. The teacher should implicitly inform students that they should discuss about the "force" of each character's utterances and how single utterances form a complete conversation. There are some possible sample questions:

(1) Why does the actress express her feelings in this way rather than saying "..."?

(2) Whether does the hearer fully understand the speaker's aim?

(3) If you are the speaker, can you express your aims in a better way?

The result of the discussion can be presented in the form of presentation or reviews.

\section{Conclusion}

As a classic theory in language in terms of communicative competence, speech act theory plays a crucial role in Pragmatics and Applied Linguistics. At the same time, we cannot neglect the function of the theory in people's daily lives. Hence, teaching speech acts in EFL classrooms cannot be neglected. Various methods can be adopted by teachers while teaching speech acts. For EFL classrooms, it is the function and usage rather than the theory itself that should be taught to the language learners in different levels. This paper gives out a discussion of various theories of speech acts as well as features and limitations of them. In second language classrooms, since language appropriateness is considered as the aim of teaching pragmatics, theories such as speech act theory, cooperative principle, and politeness should be adopted in the teaching curriculum. Accordingly, tasks can be a good method for teachers when they teach speech acts.

\section{References}

Austin, J. L. (1962). How to do things with words. Oxford: Clarendon Press.

Bardovi-Harlig, K. (1996). Pragmatics and language teaching: Bringing pragmatics and pedagogy together. In L. F. Bouton (Ed.), Pragmatics and language learning (Vol. 7, pp. 21-39). Urbana, IL: University of Illinois at Urbana-Champaign.

Bachman, L. (1990). Fundamental considerations in language testing. New York: Oxford University Press.

Boxer, D., \& Pickering, L. (1993). Problems in the presentation of speech acts in ELT materials: The case for complaints. ELT Journal, 49(1), 44-58.

Brown, G. P. (1980). Characterizing indirect speech acts. American Journal of Computational Linguistics, 6(3-4), 150-166.

Brown, G., \& Yule, G. (1983). Discourse analysis. Cambridge: Cambridge University Press.

Brown, P., \& Levinson, S. (1987). Universals in language usage: Politeness phenomena. Cambridge: Cambridge University Press.

Clark, H. H. (1979). Responding to indirect speech acts. Cognitive Psychology, 11, 430-477.

Cutting, J. (2008). Pragmatics and discourse: A resource book for students (2nd ed.). London: Routledge.

Davis, S. (1979). Perlocutions. In J. R. Searle, F. Kiefer, and M. Bierwisch (Eds.), Speech act theory and pragmatics (pp. 37-55). London: D. Reidel Publishing Company.

Gordon, D., \& Lakoff, G. (1975). Conversational postulates. In P. Cole and J. Morgan (Eds.), Syntax and semantics (Vol. 3, pp. 83-106). New York: Academic.

Larsen-Freeman, D. (2000). Techniques and principles in language teaching (2nd ed.). London: Oxford University Press.

Leung, C. (2005). Convivial communication: Recontextualizing communicative competence. International Journal of Applied Linguistics, 15(2), 119-144.

Peterson, E., \& Coltrane, B. (2003). Culture in second language teaching. CAL Digest, 3(9), 1-6. Retrieved January 22, 2006 from http://www.cal.org/resources/digest/0309peterson.html 
Searle, J. R. (1968). Austin on locutionary and illocutionary acts. The Philosophical Review, 77(4), 405-424.

Searle, J. R. (1975). Indirect speech acts. In P. Cole and J. L. Morgan (Eds.), Syntax and semantics (Vol. 3): Speech acts (pp. 59-82). New York: Academic Press.

Searle, J. R. (1976). A classification of illocutionary acts. Language in Society, 5(1), 1-23.

Taguchi, N. (2006). Analysis of appropriateness in a speech act of request in L2 English. Pragmatics, 16(4), 513-533.

Zhao, Y., \& Throssell, P. (2011). Speech act theory and its application to EFL teaching in China. Language Society and Culture, $32,88-95$. 